Review Article

\title{
Knowing When and How to Fight: COVID-19 between Viral Clearance and Immune Tolerance
}

\author{
Ahmad R. H. Utomo \\ CITO Laboratorium Klinik Semarang, Central Java, Indonesia
}

Article Info
History
Received: 12 Jul 2020
Accepted: 18 Aug 2020
Available: 31 Aug 2020

\begin{abstract}
COVID-19 is a complex disease involving immunological, vascular, and metabolic pathology caused by and consequences of beta-coronavirus SARS-CoV-2 infection. One may use Sun Tzu analogy of war to fight COVID-19 and to survive infection. When enemy has not reached the shore, gathering much intelligence is key to know how the enemy moves and who would be the most vulnerable targets of enemy attacks. Physical distancing, massive nucleic acid testing, and identification of comorbidity may prepare for the incoming enemies. Physical distancing has helped to limit transmission of the virus that mainly is due to close contacts with droplets coughed off infected individuals. Moreover, aerosolized virus particles may also contribute to spreading. Nucleic acid testing using real time PCR platform has been a diagnostic gold standard to identify infected individuals during early stage of infection. On the other hand, serological test to capture antibody against SARS-CoV-2 may be useful for immunosurveillance. Discovery of human ACE2 (angiotensin converting enzyme) protein as an obligate partner of SARS-CoV-2 viral entry has provided insights to mechanisms of serious post-infection ramifications to individuals having comorbidities such as hypertension, diabetes or heart conditions. When the enemy reaches ashore, thorough profiling of biomarkers involved in inflammation and coagulation (IL-6, lymphopenia, ground glass opacity, d-dimers, thrombocytopenia) may help predict disease progression and guide treatment strategy. While estimated $80 \%$ of infected individuals may recover on their own, the remaining $20 \%$ may require hospitalization and serious therapeutic intervention. Several clinical trials are underway such as repurposing existing drugs and evaluating efficacy of convalescence plasma therapy. Finally, vaccine development using genetic engineering may also help control the global spread if it is proven effective.
\end{abstract}

Keywords: COVID-19; SARS-CoV-2; inflammation; coagulation; diagnostic. Permalink/ DOI: https://doi.org/10.14710/jbtr.v6i2.8472

\section{INTRODUCTION}

Coronavirus disease 2019 or COVID-19 has claimed many lives and globally has not gone unabated. Started in late December 2019, COVID-19 has been described as an unusual pneumonia affecting initially people who had attended and traded in wet animal market in Wuhan. ${ }^{1}$ Soon thereafter the causative viral agent has been identified and its genomic sequence has been made public. The RNA virus is named SARS-CoV-2 because its genomic homology to SARS-CoV-1, a beta coronavirus that causes SARS (Severe Acute Respiratory Syndrome) in 2002-2004. ${ }^{2}$ Moreover, just like SARS-CoV-1, SARS-CoV-2 also recognizes and binds human ACE2 (Angiotensin Converting Enzyme). Unlike SARS that had been controlled within 8 months after infecting 8,100 people in selected territories, COVID-19 has spread globally within just 5 months infecting 2.6 million people and has overwhelmed health care facilities worldwide ${ }^{3}$ and sometimes claimed many lives of professional healthcare workers. ${ }^{4}$ As of 29th of June 2020, there are over 10 million laboratoryconfirmed cases worldwide with more than 0.5 million deaths.

As the details of COVID19 have continued to be unfolded, this review article aims to provide some key features that make COVID19 unique vis a vis other 
coronavirus associated diseases namely SARS and MERS and helps giving an overview of challenges in controlling the disease.

\section{BATTLE PLAN}

Imagery of fighting SARS-Cov-2, causative agent of COVID-19 invokes the sight of an all-out immunological war pitting human hosts against invisible invading pathogens. However, immunology also tells us that knowing when and how to fight is key to curb transmission. Moreover, the ultimate outcome of any battle against pathogens is to avoid fatal outcome and to minimize long-term morbidity amongst survivors. Efforts to curb COVID-19 pandemic do require multipronged approaches and should have awareness about timing and stages of disease progression. Not only knowing how to clear infection but also how to survive infections. This is where mapping out battle plan is essential to guide concerted effort about when and how to fight.

The battle plans may draw up two scenarios mainly based on enemy movement. First, when the enemy has not reached a shore, gathering intelligence is key. Since COVID-19 outbreak has initiated in China, many countries have formed defensive positions. At this stage, intelligence gathering is critical to address the following questions. What is the causative agent of COVID-19? What does COVID-19 do to the body? How does SARSCoV-2 spread among the people? How to detect individuals infected with SARS-CoV-2? However, once the enemy has breached defensive lines, the second scenario would implement combinatory efforts of clearing viral infection and building up immune tolerance. In addition, vulnerable individuals such as those with hypertension, diabetes, obesity and certain heart comorbidities should be paid close attentions for getting worst clinical outcome

\section{FIRST SCENARIO: Keeping the enemy at Bay}

"If you know the enemy and know yourself, you need not fear the result of a hundred battles" (Sun Tzu, The Art of War).

Even though there is already strong association between the presence of viral RNA of SARS-CoV-2 and clinical symptoms of COVID-19 (fever, dry cough, myalgia, malaise, loss of smells, ground glass opacity) 5,6 formal proof to demonstrate causality is needed. SARS-CoV-1 has been defined as a causative agent of SARS because it has fulfilled Koch Postulate in mouse model expressing human ACE2 (Angiotensin Converting Enzyme) receptors. ${ }^{7}$ Fulfillment of Koch Postulate is important to build confidence in development of diagnostic, preventive, and treatment strategies.

\section{A. What is the causative agent of COVID-19?}

In case of COVID-19, several laboratories have used many approaches to prove causality of SARS-CoV-2 infection and appearance of the disease. First, transgenic mice that express human ACE2 have been made using transgenic cassette, ${ }^{8}$ or gene editing. ${ }^{9}$ Adenoviral infection carrying human ACE2 is another strategy to introduce human $\mathrm{ACE} 2,{ }^{10}$ an important receptor required for SARS-CoV-2 entry. Second, transgenic mice expressing human ACE2 have been challenged with SARS-CoV-2 viral particles and the results show many recapitulations of human diseases. ${ }^{8,10}$ Pulmonary edema and massive leucocytes infiltration have been observed consistently in infected human ACE2 transgenic mice. Furthermore, peaks of viral load have been observed and virus particles have been recovered from the infected lungs within few days that mimic human pathophysiology of COVID-19. ${ }^{8,10}$ These phenotypes are not found in wild type mice that do not express human ACE2 in spite of deliberate SARS-CoV-2 infection proving exquisite specificity. These key results fulfill Koch postulate and provide theoretical foundation to design diagnostic strategy, discover novel drugs, and elucidate molecular pathology. ${ }^{11}$ Moreover, these ACE2 mice will serve as preclinical models to test putative or novel antiviral drugs and vaccine efficacy.

While SARS-CoV-2 is now firmly established as a causative agent of COVID-19, there was a lingering question "where does it come from"? The zoonotic origin of COVID-19 has been implicated by high genomic homology or $96 \%$ identity between SARS-CoV-2 and bat coronavirus. ${ }^{12}$ To address many speculations that SARSCoV-2 was a man-made manipulation, a careful structural genomic analyses of the receptor binding domain (RBD) of Spike SARS-CoV-2 has been performed. ${ }^{2}$ The results show that there are many mutations in the Spike RBD of SARS-CoV-2 that diverge from SARS-CoV-1, a coronavirus that causes SARS. In spite of the large genetic divergence, both RBDs from these coronaviruses are able to bind human ACE2. Moreover, several experiments have confirmed these specific binding and demonstrated even higher affinity of SARS-CoV-2 RBD to ACE2 than SARS-CoV-1.13-14 Therefore, these genetic and biochemical data has put to rest the possibility of the virus being a man-made creation. $^{2}$ Furthermore, many laboratories have continued to search for animal reservoirs of SARS-CoV2 and explored the possibility of genomic recombination's either within bat coronaviruse ${ }^{15}$ or with other coronaviruses belonging to pangolin or other unidentified animals. ${ }^{16}$ These studies may pave better understanding of zoonotic disease evolution and transmission to human.

\section{B. What does SARS-CoV-2 do to the body}

COVID-19 patients also show some abnormal immunological and vascular profiles that relate to pathological inflammation and coagulation. Relatively high circulating interleukin-6 (IL-6), high NLR (neutrophils to leucocytes ratio), lymphopenia, presence of radiological ground glass opacity, high d-dimers, thrombocytopenia, and low platelet counts. ${ }^{12}$ Recent series of autopsy studies on deceased COVID-19 patients also show high prevalence of fatal pulmonary thromboembolism, diffuse alveolar damage and presence of viral RNA in lung parenchyme. ${ }^{17-20}$ Some studies also suggest cytopathic endothelial damage and abnormal blood vessel formations. ${ }^{21}$

\section{Tracking enemy movement (Modes of SARS-CoV- 2 transmission)}

SARS-CoV-2 has similar characteristics with SARSCoV-1 and MERS-CoV (causing SARS and MERS, 
respectively) in terms of genetic backbone (that is homologous to bat coronaviruses genome), spillover zoonotic infection leading to human to human transmission, and shared clinical symptoms (dry cough, myalgia, fever, gastrointestinal and pulmonary involvements). ${ }^{22}$ However, there are notable differences such as high transmission or Ro reproduction numbers (2.5, 2.4, and 2 for SARS-CoV-2, SARS-CoV-1, MERS$\mathrm{CoV}$, respectively). Rapid timing to reach peaks of viral load (SARS-CoV-2 takes 3 to 5 days while SARS-CoV17 to 10 days), high affinity to ACE2 receptor (SARSCoV-2 is 10 times higher than SARS-CoV-1) and SARS-CoV-2 tropism to upper respiratory organs (while SARS-CoV-1 is mostly in lower respiratory organs) (22). Collectively, these unique features make SARSCoV-2 transmission more difficult to control and consequently more infectious than SARS-CoV-1 and MERS-CoV.

Close examination of spike proteins of SARS-CoV2 may also explain efficient viral transmission when compared to SARS-CoV-1. Spike proteins contain receptor binding domain (RBD) that is important to bind human proteins that is essential for viral binding and fusion. Spike proteins of SARS-CoV2 has ten times higher affinity to bind human ACE2 receptor than SARS-CoV- $1 .{ }^{13}$ Furthermore, there is a short insertion of four polybasic amino acids within Spike protein that serve as furin binding sites that allow efficient fusion to human cells. ${ }^{23,24}$ Recent in vitro analysis of SARS-CoV2 spike protein also demonstrated that G614 variant may infect human cells more efficiently and produce higher numbers of viral particles than D614 variant. ${ }^{25}$ The change from Aspartic acid to Glycine at codon 614 may lead to efficient virus to human cell fusion. This result has been proposed to explain the predominance and viral existence of D614 variant in North America and Europe. However, this putative explanation of G614 variant of SARS-CoV-2 rapid transmission does not correlate with COVID-19 severity (26).

SARS-CoV-2 transmission is largely through close contacts when droplets of infected individuals are picked up by other individuals. Other studies suggest that some medical procedures in hospitals may also create aerosols that may carry virus particle in the environments. ${ }^{27}$ In public settings, the use of face masks has been highly recommended to prevent transmission. Since SARSCov-2 viral load may build up rapidly in upper respiratory organs of individuals with or without mild symptoms, contact tracing is essential and deployment of proper diagnostic is a must. Recently, the prospect of airborne transmission of the virus raise serious issue after the description of viral transmission in a restaurant in Guangzhou and an incident of choir practice in the United States attended by 60 people leaving 33 confirmed cases and 2 deaths. ${ }^{28,29}$ These incidents outline the risk of airborne transmission due to gathering of human activity in enclosed space for hours.

In addition to proper diagnostic to halt virus transmission, there are three public health policy models to control COVID-19. First, comprehensive lockdown has been practiced by China in order to halt public mobility for several weeks and discourage viral transmission. ${ }^{30}$ Second, massive RTPCR testing has been implemented by South Korea to identify and confirm every possible suspect of SARS-CoV-2 carriers. ${ }^{31}$ Lastly, encouragement of public gathering for young people and limiting vulnerable population (elderly population and people with comorbidity) has been enacted in Sweden. ${ }^{32}$ The first two models have led to 'flattening the curve' where new cases have been halted. On the other hand, Sweden experience has ended up with highest mortality rates amongst Nordic countries who implemented strict measures of public mobility. ${ }^{33-34}$

\section{How to detect the enemy}

Publications of SARS-CoV-2 genome have also prompted global efforts to design RTPCR test and dissemination of RTPCR diagnostic kits. ${ }^{35,36}$ Primary aim of COVID-19 is to break chain of transmission by identifying individuals who are infected with SARSCoV-2. Individuals with confirmed RTPCR results would be isolated in order to protect population at large from getting infections. Secondly, diagnostics may help to monitor recovery of COVID-19 patients by detecting the presence of viral RNA in the patient bodies. ${ }^{37}$ Patients who are in the path of recovery may be tested two times with RTPCR within two days. When the RTPCR results show two negative results in two consecutive days, patients are eligible to be discharged. ${ }^{38}$ However, this protocol may be modified in some countries who adopt 3 weeks monitoring of clinical parameters as readout of recovery since shortage of RTPCR may be allocated to perform contact tracing of infected individuals.

There are three steps in COVID-19 diagnosis: preanalytical, analytical, and post analytical steps. To avoid diagnostic inaccuracy, care must be given during pre-analytical step which include specimen collection from ideal anatomical sites, specimen preservations and rapid and robust RNA extractions. ${ }^{39,40}$ Nasopharyngeal and oropharyngeal specimens are usually collected together from suspected individuals who are at risk of contracting the virus due travel history to or from epidemic areas, close contact with confirmed cases of COVID-19, or appearance of symptoms. Recently, saliva may also serve as alternative samplings and has been demonstrated to have similar accuracy to conventional samplings with less risk to healthcare workers. ${ }^{41}$ Asymptomatic or pre-symptomatic individuals are also a concern because up to $50 \%$ infected individuals do not appear to be sick. ${ }^{42}$ Yet, studies have shown that viral loads are high in these individuals rendering transmission is likely.

Specimen preservation especially from remote areas must reach laboratory using proper VTM and temperatures to prevent viral RNA degradation. Lastly, RNA extraction can become bottleneck in RTPCR procedures, especially when there is shortage of RNA extraction reagents due to high demands from laboratory performing high volume testing. Therefore, automated RNA extraction is preferable to obtain consistent results. Alternatively, direct RTPCR protocol has been proposed to skip RNA extraction step and speed up testing procedures. $^{43}$

During analytical step, the choice of methods and analyte is important. Due to backlog of RTPCR testing, some countries have used lateral flow-based antibody testing that has rapid turnaround time, typically completed within 15 minutes and can be performed as 
point of care testing requiring as little as a drop of blood. Although some governments have deployed this tactic, emerging literatures show that rapid antibody testing that seek to detect anti-viral spike proteins of SARS-CoV-2 antibodies may not be appropriate to perform diagnostic due to low sensitivity in early phase of infections, where virus particle is at the highest. ${ }^{44}$ During this early phase, infected individuals may transmit the virus to others while they have not developed antibodies against the virus, which typically appear 7 to 14 days after first onset of symptoms. Reported diagnostic sensitivity of lateral flow test during early infection phase is between 20$40 \% .{ }^{44,45}$ In comparison, RTPCR based testing diagnostic sensitivity is between $60-70 \%$. Due to this low sensitivity the use lateral-flow based diagnostics is highly discouraged except in the setting of clinical validation or immunosurveillance studies to estimate the burden of infection within certain community or territory. Semiquantitative reversed transcriptase real time RTPCR is currently a gold standard to detect RNA of SARS-CoV-2. Sample collection must be taken within less than 5 days after first symptoms appear. Most RTPCR primers are targeting ORF1, RDRP, and N genes of SARS-CoV-2 where the mutations in these regions are relatively rare i.e. less than $1 \%{ }^{46}$

\section{E. To isolate source of infections}

COVID-19 outbreak in cruise ship Diamond Princess shows the importance of contact tracing and extend RTPCR testing to asymptomatic individuals. Japanese authority reports that at the end of massive RTPCR testing of all passengers and crews demonstrated that asymptomatic individuals contribute up to $50 \%$ of total RTPCR confirmed cases. ${ }^{47}$ Furthermore, many studies have found risk of viral transmission by asymptomatic individuals to susceptible individuals $(48,49)$.

\section{F. To monitor recovery of COVID-19 patients}

As disease progresses, majority of COVID-19 patients have shown clinical improvement and demonstrated low to undetectable viral RNA. While some nasopharyngeal swabs of recovering patients are standard methods to monitor viral burdens, some studies suggest performing rectal swab RTPCR ${ }^{50,51}$ Viable viral particles have been recovered from fecal specimens and support the possibility of fecal oral transmission. Environmental monitoring also shows presence of viral RNA in waste centers and toilets where patients are being treated. ${ }^{40}$ There are also concerns that previously recovered individuals may get disease recurrence although the symptoms may be milder than the initial infection. ${ }^{52}$ Nevertheless, to resolve the issues of 'reinfection', 'recurrence' or technical difficulties in specimen collection may not be easy in these individuals (53).

SECOND SCENARIO: Meeting enemy at the gate (viral clearance and/or immune tolerance)

\section{A. Initial phase of infection}

Infection of SARS-CoV-2 begins with binding of viral Spike protein to human ACE2 receptor. Upon binding, human serine protease TMPRSS2 cleaves off S1 subunit of viral Spike protein exposing S2 subunit which initiates fusion to host cell membranes leading to invagination and endocytosis. ${ }^{23} \mathrm{Up}$ to $80 \%$ of infected individuals who have either asymptomatic to mild or moderate symptoms, viral infections are cleared early and effectively. Fusion of viral particles and release of viral RNA trigger a series of immune activation namely Pattern Recognition Receptor (PRR) leading to interferons production. Interferon pathway is a major innate immunity defense mechanism to clear viral infection through recruitment of macrophages, neutrophils and natural killer cells. ${ }^{54}$ In addition, dying or apoptotic infected cells are phagocytosed by macrophages and initiated the release of proinflammatory cytokines such as IL-1, TNF alpha and IL6 promoting further recruitment of immune cells. Direct uptake of viral particles or indirect by phagocytosis of dying cells by dendritic cells or professional Antigen Presenting Cells (APC) will initiate activation of adaptive immune cells. APC loads and presents epitope (antigenic peptides) of viral particle to T helper cells and activates them. $\mathrm{T}$ helper cells then promote differentiation of antibody producing B cells and cytotoxic CD8 T cells. ${ }^{54}$ Combination of viral specific antibody production and activation of circulating cytotoxic $\mathrm{T}$ cells are important to ward off future infection. Successful control of viral infection is also shown by the declining amount of viral RNA and the appearance of IgG anti SARS-CoV-2.

Majority of individuals who survive the initial phase of infection often show no symptoms or at best mild symptoms requiring no hospitalization. Interestingly, antibody titers against SARS-CoV-2 that are being generated in these individuals for some unknown reasons are low and not sustained at high level, especially when compared to COVID-19 patients with serious conditions. ${ }^{55}$ It is not clear whether recovery from infections is determined either from certain level of high plasma neutralizing antibodies or activation of adaptive immunity that is driven by circulating memory T-cells. At this stage, neither viral burden nor neutralizing antibody predict recovery of infections.

There are also some anecdotal reports that individuals who have recovered from COVID-19 remain vulnerable to another infection, although the clinical manifestation is usually mild. Moreover, there is also a need for long term surveillance amongst survivors because there is a risk to develop diabetes, lung fibrosis, and lung cancers. ${ }^{56,57}$ ACE2 is also expressed in pancreatic cells producing insulin and SarS-CoV-2 infection may induce apoptosis and compromise the ability to produce insulin. The appearance of ground glass opacity in the lung may also implicate some degree of inflammation that has long term health consequences such as breathing and promotion of lung tumorigenesis.

Children and individuals with $\mathrm{O}$ blood type are having better position to avoid severe COVID-19. Some have suggested that children tend to have "high" level of ACE2 expression which may save them from getting uncontrolled inflammation. ${ }^{58}$ Although ACE2 is an essential receptor for SARs-CoV-2 infection, ACE2 is an important enzyme to convert Angiotensin 2 (pro inflammatory and vasoconstrictor) into Angiotensin 1-7 (anti-inflammatory and vasodilator). ${ }^{59}$ Therefore, high ACE2 expression actually helps maintain 'anti inflammation' millieu as the body attempts to clear viral infections. 
In contrast to children, elderly population is particularly susceptible to COVID-19 and has high risk of morbidity and mortality. The expression of ACE2 has been thought to be lower in aging adults than children. Although low ACE2 expression being SARS-CoV-2 obligate receptor may intuitively confer less susceptibility to infection, post infection actually leads to internalization of surface ACE2 expression leading to aggravation of hypertension and inflammation(60). Old age is also associated with immune-senescence and inflame-aging, a combination leading to inability to clear viral infection effectively. ${ }^{61}$ Furthermore, the prevalence of comorbidities such as diabetes, cardiovascular diseases, and hypertension are more common in old age. $^{62}$

Blood type $\mathrm{O}$ is also found to have the lowest risk of severe infections than other blood type, especially blood type A as demonstrated by clinical study in China and genome wide screening data in Europe $(63,64)$. The protective effect of type $\mathrm{O}$ blood is related to the presence of anti A antibodies which target certain glycosylated antigens. This protective factor is also found during SARS. Heavily glycosylated Spike protein of SARS-CoV-2 like SARS-CoV-1 are needed to bind ACE2 in order to initiate infection. However, anti A antibody targeting glycosylated peptide may also interfere with effective binding of spike to ACE2 hence conferring some protection. ${ }^{65}$

Since pneumonia is one of the COVID-19 hallmarks, underlying respiratory diseases affecting lung physiology such as chronic obstructive pulmonary disease (COPD) and lung cancer are expected to confer high risk of morbidity and/or mortality. Recent study and meta-analysis review indeed confirm the expectation that COVID-19 patients with COPD have poor prognosis than patients without COPD. ${ }^{66,67}$ High fatality rate in COVID-19 patients with lung cancer has been observed recently. ${ }^{68}$ Therefore, extra precautionary measures must be placed to protect individuals with lung diseases from contracting COVID19.

There is another speculation that national programmed of BCG vaccination may protect some community against COVID-19. ${ }^{69}$ Northern America and Western Europe who do not mandate BCG vaccination are relatively hard hit compared to some Asian nations who are still running obligatory $\mathrm{BCG}$ vaccination. The protective mechanism of previous vaccination against COVID-19 invoke the concept of 'trained immunity', where non-specific immunity against unrelated pathogens may induce some resistance to other pathogens (70). However, the role of BCG vaccination has been challenged recently and calls for prospective study to clear up the debates. ${ }^{71}$

\section{B. Second phase of viral infection}

For the remaining $20 \%$ of infected individuals, viral clearance is either unsuccessful and/or ending up with futile inflammation known as cytokine storms. ${ }^{72}$ Like COVID-19 predecessors SARS and MERS, inflammation also triggers pulmonary coagulopathy and occasionally disseminated intravascular coagulation..$^{73,74}$ When SARS-CoV-2 enters the respiratory organs, ACE2 expressing alveolar epithelial cells are the virus main targets. In addition, pulmonary vasculatures that are made up of ACE2 expressing endothelial cells are also susceptible to SARS-CoV-2 infection. Ensuing endothelial damages, pro coagulation thrombins are released and initiate coagulation cascades as shown in high level of d-dimers and low level of platelet counts (thrombocytopenia) which are associated with severe COVID-19 cases and mortality risk. Therefore, when left unchecked, thrombi formation may impede pulmonary blood circulation leading to hypoxia and compromising oxygen exchange. ${ }^{75}$

Studies on severe and critical COVID-19 patients also reveal abnormal immunological reads out. $^{76}$ Pro inflammatory IL-6 is found to be elevated and explain high burden of immune infiltration in the lung exacerbating tissue damage. High IL-6 is also consistent with lymphopenia, where there is a drop of circulating lymphocytes. Lymphocytes reduction may be explained by two mechanisms. Lymphocytes may leave circulation to enter alveolar spaces creating tissue damages. ${ }^{21}$ Alternatively, SARs-CoV-2 may directly infect and kill lymphocytes through CD147 (77). In spite of having have low level expressions of ACE2, lymphocytes remain sensitive to SARCoV2 infection, because spike proteins of SARS-CoV-2 have 10 times higher affinity to bind Ace2 than SARS-CoV-1.

Therefore, there is a therapeutic challenge for patients who are undergoing the next phase of infection where there is a dangerous liaison between inflammatory selfinjury and ongoing viral presence. While high viral burden may predict progression to severe cases of COVID-19, reduction of viral burden in itself may not lead to automatic recovery. ${ }^{78}$

Therefore, aggressive measures to block viral entry or replication may seem futile once the disease has become progressive into severe symptoms. Clinical trials of hydroxychloroquine which aims to block viral entry by increasing $\mathrm{pH}$ of the endosome has been shown to be ineffective in severe COVID-19 patients. Acidic endosomes have been thought to be important to assemble viral proteins to produce virions. Although in vitro data suggest successful blocking of SARS-CoV-2 by hydroxychloroquine, ${ }^{79}$ WHO SOLIDARITY $^{80}$ clinical trial has announced to stop $\mathrm{HC}$ arm based on interim analysis demonstrating lack of benefit. Another trial in Brazil also shows unacceptable $\mathrm{HC}$ toxicity in severe COVID-19 patients. $^{81}$

Combinations of protease inhibitors Ritonavir and Lopinavir have been used to treat HIV patients. Viral proteases are also required for proper assembly of virus particles. However, recent clinical trial also fails to demonstrate benefit. ${ }^{82}$ Lastly, antiviral drug remdesivir, which is an adenosine analogue to interfere with SARSCoV-2 RDRP enzyme during viral RNA replication also has mixed results. ${ }^{83}$ Randomized clinical trial in China fails to show statistically significant benefit of remdesivir (84). However, another RCT has shown that remdesivir may induce some clinical improvement in the preliminary report. $^{85}$

Convalescence plasma (CP) therapy is an example to control viral infection in severe cases of COVID-19. ${ }^{86}$ The idea of CP rests on the assumption that individuals who are recovered from COVID-19 may contain levels of neutralizing antibody against SARS-CoV-2 and may 
help current patients to control viral burden. $\mathrm{CP}$ has been used during SARS with some inconclusive results because SARS itself has been controlled fairly quickly. There are some case reports of few patients with severe COVID-19 who are recovered when given CP. A large retrospective study from China also reports clinical improvement. ${ }^{87}$ However, recent meta-analysis has demonstrated the difficulty to draw conclusion of $\mathrm{CP}$ efficacy due to lack of clear results obtained from existing randomized clinical trial. ${ }^{88}$ Recent clinical trial has been discontinued due to difficulty to recruit severe patients as subjects, ironically as a result of successful lockdown. ${ }^{89}$

Interim analyses of the Chinese RCT shows that there is a consistent reduction of viral burden that is estimated from the $\mathrm{Ct}$ value of $\mathrm{RT}$ PCR ${ }^{89} \mathrm{Ct}$ values under 15 is generally indicative of high viral burden. Both severe and critical patients receiving $\mathrm{CP}$ show consistent reduction of viral burden after treatment. However, this reduction does not associate directly with clinical improvement. ${ }^{89}$ It is not clear whether failure to see CP efficacy is due to lack or insufficient level of neutralizing antibody $(\mathrm{Nab})$ in $\mathrm{CP}$ donors. In fact, studies on neutralizing antibody dynamic show that severe COVID-19 patients have higher level of $\mathrm{Nab}$ than individuals who have recovered from COVID-19. Therefore, much to be learned to explain why some severe patients do get clinical improvement after CP therapy.

Another innovative approach to block SARS-CoV-2 virus infection is inject soluble recombinant human ACE2. ${ }^{90}$ There are two reasons why this approach may work as supported by recent successful preclinical data on animal model expressing human ACE2. First, the soluble ACE2 may act like decoy and biological sink to attract SARS-CoV-2. ${ }^{91}$ Second, the circulating ACE2 may capture and convert Angiotensin 2 into Ang 1-7. Infection of SARS-CoV-2 may cause downregulation of endogenous ACE2 leading to elevated levels of Ang 2 which promote inflammation. ${ }^{92}$ Injection of soluble ACE2 may control and bring down Ang2.

While antiviral studies have not yield conclusive efficacy to treat COVID-19, drugs to control inflammation and/or maintain physiological function such as blood pressure and blood glucose have shown some benefits.

\section{Controlling inflammation (immune tolerance)}

Generally, reducing inflammation in viral infected individuals runs risk of getting secondary bacterial or nosocomial infections. IL-6 is one of the inflammatory cytokines that is consistently upregulated and may serve as predictor of severe COVID-19 cases. Tocilizumab is a monoclonal antibody targeting IL-6 that is currently undergoing clinical trial in severe COVID-19 cases. $^{93}$ BTK inhibitor is another example of repurposing drug that is originally given as anti-cancer drugs. The inhibitor targets the cells that are expressing IL-6 at high levels. ${ }^{94}$

Recovery Clinical Trial in the United Kingdom shows that Dexamethasone may reduce mortality risk to $30 \%$ in severe cases of COVID-19 but not in mild cases (95, 96). Dexamethasone, a well-known antiinflammatory drug with plethora of side effects may not be an ideal drug but the results show that reducing inflammatory burden is as important as viral clearance.

\section{Controlling coagulation}

Pulmonary coagulopathy and occasionally disseminated intravascular coagulation have been observed in COVID-19 patients. $^{74,97,98}$ Autopsy reports also show that the majority of fatal COVID-19 cases have shown abnormal coagulation especially in the lung. However, giving blood thinner or anti-coagulant may also run risk of bleeding. Therefore, timing to give blood thinner must be paid close attention. Several clinical trials are ongoing to see the effect of anti-coagulations. ${ }^{99,100}$

\section{Controlling blood pressure}

Hypertension has been identified as a risk factor associated with severe case of COVID-19. ${ }^{101}$ This is due to generally lack or reduced level of ACE2 expression in hypertensive, diabetic, and some patients with cardiac conditions. ${ }^{102} \mathrm{ACE} 2$ is one of the homeostasis regulator of RAS system renin-angiotensin-aldosterone system. Angiotensin 2, a substrate of ACE2 is a potent vasoconstrictor and inducer of inflammations. ACE2 is converting Angiotensin 2 into Angiotensin 1-7 that has opposite effect to Ang2 i.e. vasodilators and antiinflammation. While hypertensive and diabetic patients' risk of infection is identical to individuals who have no comorbidities, hypertension and diabetic poses significant risk to get a severe case of COVID-19. Hypertensive and diabetic patients have already risk of being high inflammatory status and prone to undergo cytokine storms. ${ }^{102}$

Since SARS-CoV-2 binds to ACE2, there are concerns that hypertensive patients may be at risk to have higher susceptibility to be infected when they do not stop consuming hypertension drugs. The concern is based in animal studies where treatments of ACE (angiotensin converting enzyme) inhibitor or ARB (angiotensin receptor blockers) lead to elevated expression of ACE2. ${ }^{103,104}$ However, recent studies show that the consumptions of ACEi and ARB by hypertensive patients are not associated with higher risk of mortality and morbidity than those who do not consume. ${ }^{105-107}$ In one study, anti-hypertensive drug consumption may actually associate with better clinical outcome. ${ }^{108}$ Therefore, whether there is an unintended benefit of ACEi and ARB to improve COVID-19 outcome should be tested in RCT. Meanwhile American Heart Association has recommended patients to continue with their hypertensive medications even when diagnosed with COVID-19. ${ }^{109}$

\section{Controlling blood glucose}

Recent gene expressions study suggest that diabetic patients may have been associated with high level expression of ACE2, receptors for SARS-CoV-2 Spike proteins. ${ }^{110}$ Moreover, hyperglycemia commonly found in diabetic patients may also induce ACE2 expression. Whether elevated ACE2 expression correlates with high burden of SARS-CoV-2 virus remain to be seen. However, diabetic patients do have some inflammation within their vascular system. Therefore, infection of SARS-CoV-2 may exacerbate the already pro inflammatory and pro coagulatory status in diabetic 
patients. Interestingly, COVID-19 patients with diabetes may have higher chance of survival when they are able to control their blood sugar. ${ }^{111}$

\section{TOWARD END OF A PANDEMIC?}

'The supreme art of war is to subdue the enemy without fighting.' (Sun Tzu)

Through strict public health policy measures, SARS and MERS have been eliminated in matter of months with much less victims than what COVID-19 has claimed to date. This rapid elimination could also be attributed to high case fatality rate of SARS and MERS ie $10 \%$ and $30 \%$, respectively. Therefore, victims who fall ills are relatively easy to be identified and isolated. However, complete elimination of SARS and MERS has left substantial gaps in our knowledge about pathogenic coronavirus behavior. Vaccines against SARS and MERS have not been developed forcing the scientific community to start developing COVID-19 from scratch.

Fortunately, the advance of bioinformatics and speed of Next Generation Sequencing have helped warp-speed the production of modern vaccines such as DNA/RNA vaccines and recombinant antigens that are relatively inexpensive than the traditional approach making vaccine seed using inactivated or weakened virus approach. ${ }^{12,113}$ However, though initial production of vaccine seeds may take short time, there is a hurdle of testing the efficacy of these variety of vaccines in protecting the population from future infections.

There are several concerns about how to prove vaccine efficacy. ${ }^{114}$ First, individuals who have mild or asymptomatic COVID-19 and are recovered from COVID-19 do not have sustainable level of antibody. ${ }^{55}$ Therefore, the putative protection conferred by the vaccines should be described in detail regarding the level and sustainability of neutralizing antibody being generated, the production of mucosal immunity to intercept the virus in respiratory organs and the presence of memory T cells. Secondly, vaccines that produce low or insufficient level of neutralizing antibody may lead to ADE (antibody dependent enhancement) of SARSCOV-2 infection with worst symptoms. These low levels anti SARS-COV-2 antibody being produced by poorly validated vaccine forms immune complex with actual virus. These unintentional immune complex formations may illicit violent immune response mediated by $\mathrm{Fc}$ gamma receptors of the innate immune cells. ${ }^{115}$ Moreover, innate immunity would be inadvertently a target of infection themselves compromising the first line of defenses against incoming viruses. Although ADE has been well described in Dengue Hemorrhagic Fever, ADE in SARS-CoV-2 has not been documented. However, ADE remains a theoretical possibility due to the speed of vaccine development which may have risk of overlooking the details of vaccine validation before rolling it out to the population.

\section{CONCLUSIONS}

COVID-19 pandemic has taught many lessons regarding our state of knowledge. Apparently neither existing knowledge nor experiences are able to stop the global reach of COVID-19 transmission. Apparently, medical intervention alone is insufficient but must involve social cooperation such as physical distancing and personal hygiene. The relatively high viral burden without necessarily showing symptoms does contribute to the rapid transmission. Therefore, innovation in pointof-care diagnostics is key to identify the enemy as early as possible. The complex inflammatory and coagulation impact of COVID-19 must be understood in detail in order to mount precise treatment and patient stratification. ${ }^{99}$ Complete biomarkers profiling using comprehensive molecular tools could be important to predict patients who are most likely to recover or progress to withstand cytokine storms. However, there is opportunity for global cooperation to advance scientific understanding of drug discovery and vaccine development. At the end of the day, human body of knowledge and resilience will prevail, and we shall pay tribute to those who could not see the end of this great pandemic.

\section{REFERENCES}

1. Zhu N, Zhang D, Wang W et al. A Novel Coronavirus from Patients with Pneumonia in China, 2019. N Engl J Med. 2020;382:727-733.

2. Andersen KG, Rambaut A, Lipkin WI, Holmes EC, Garry RF. The proximal origin of SARS-CoV-2. Nature Medicine. 2020;26:450-452.

3. Baden T, Maia Chagas A, Molloy J, Prieto Godino L. Leveraging Open Hardware to Alleviate the Burden of COVID-19 on Global Health Systems. 2020

4. Ing EB, Xu QA, Salimi A, Torun N. Physician deaths from corona virus (COVID-19) disease. Occup Med (Lond). 2020

5. Guan WJ, Ni ZY, Hu Y et al. Clinical Characteristics of Coronavirus Disease 2019 in China. N Engl J Med. 2020;382:1708-1720.

6. Zhang L, Zhu F, Xie L et al. Clinical characteristics of COVID-19-infected cancer patients: a retrospective case study in three hospitals within Wuhan, China. Ann Oncol. 2020;31:894-901.

7. Osterhaus AD, Fouchier RA, Kuiken T. The aetiology of SARS: Koch's postulates fulfilled. Philos Trans R Soc Lond B Biol Sci. 2004;359:10811082.

8. Bao L, Deng W, Huang B et al. The pathogenicity of SARS-CoV-2 in hACE2 transgenic mice. Nature. 2020

9. Sun SH, Chen Q, Gu HJ et al. A Mouse Model of SARS-CoV-2 Infection and Pathogenesis. Cell Host Microbe. 2020

10. Hassan AO, Case JB, Winkler ES et al. A SARSCoV-2 Infection Model in Mice Demonstrates Protection by Neutralizing Antibodies. Cell. 2020

11. Lutz C, Maher L, Lee C, Kang W. COVID-19 preclinical models: human angiotensin-converting enzyme 2 transgenic mice. Hum Genomics. 2020;14:20.

12. Zhou P, Yang X-L, Wang X-G et al. A pneumonia outbreak associated with a new coronavirus of probable bat origin. Nature. 2020;579:270-273.

13. Shang J, Ye G, Shi K et al. Structural basis of receptor recognition by SARS-CoV-2. Nature. 2020;581:221-224. 
14. Wang Q, Zhang $\mathrm{Y}$, Wu L et al. Structural and Functional Basis of SARS-CoV-2 Entry by Using Human ACE2. Cell. 2020;181:894-904.e9.

15. Boni MF, Lemey $\mathrm{P}$, Jiang $\mathrm{X}$ et al. Evolutionary origins of the SARS-CoV-2 sarbecovirus lineage responsible for the COVID-19 pandemic. Nat Microbiol. 2020

16. Lam TT, Jia N, Zhang YW et al. Identifying SARS$\mathrm{CoV}$-2-related coronaviruses in Malayan pangolins. Nature. 2020;583:282-285.

17. Carsana L, Sonzogni A, Nasr A et al. Pulmonary post-mortem findings in a series of COVID-19 cases from northern Italy: a two-centre descriptive study. Lancet Infect Dis. 2020

18. Edler C, Schröder AS, Aepfelbacher M et al. Dying with SARS-CoV-2 infection-an autopsy study of the first consecutive 80 cases in Hamburg, Germany. Int J Legal Med. 2020;134:1275-1284.

19. Wichmann D, Sperhake J-P, Lütgehetmann $M$ et al. Autopsy Findings and Venous Thromboembolism in Patients With COVID-19. Annals of Internal Medicine. 2020

20. Barton LM, Duval EJ, Stroberg E, Ghosh S, Mukhopadhyay S. COVID-19 Autopsies, Oklahoma, USA. Am J Clin Pathol. 2020;153:725733.

21. Ackermann M, Verleden SE, Kuehnel $M$ et al. Pulmonary Vascular Endothelialitis, Thrombosis, and Angiogenesis in Covid-19. N Engl J Med. 2020

22. Petersen E, Koopmans M, Go U et al. Comparing SARS-CoV-2 with SARS-CoV and influenza pandemics. Lancet Infect Dis. 2020

23. Hoffmann M, Kleine-Weber H, Pöhlmann S. A Multibasic Cleavage Site in the Spike Protein of SARS-CoV-2 Is Essential for Infection of Human Lung Cells. Mol Cell. 2020;78:779-784.e5.

24. Jaimes JA, Millet JK, Whittaker GR. Proteolytic Cleavage of the SARS-CoV-2 Spike Protein and the Role of the Novel S1/S2 Site. iScience. 2020;23:101212.

25. Korber B, Fischer WM, Gnanakaran $S$ et al. Tracking changes in SARS-CoV-2 Spike: evidence that D614G increases infectivity of the COVID-19 virus. Cell. 2020

26. Grubaugh ND, Hanage WP, Rasmussen AL. Making sense of mutation: what D614G means for the COVID-19 pandemic remains unclear. Cell. 2020

27. Jayaweera M, Perera H, Gunawardana B, Manatunge J. Transmission of COVID-19 virus by droplets and aerosols: A critical review on the unresolved dichotomy. Environ Res. 2020;188:109819.

28. Morawska L, Tang JW, Bahnfleth W et al. How can airborne transmission of COVID-19 indoors be minimised[letter]. Environ Int 2020;142:105832.

29. Hamner L, Dubbel P, Capron I et al. High SARSCoV-2 Attack Rate Following Exposure at a Choir Practice - Skagit County, Washington, March 2020. MMWR Morb Mortal Wkly Rep. 2020;69:606-610.

30. Lau H, Khosrawipour V, Kocbach $P$ et al. The positive impact of lockdown in Wuhan on containing the COVID-19 outbreak in China. J Travel Med. 2020;27
31. Kwon KT, Ko J-H, Shin H, Sung M, Kim JY. DriveThrough Screening Center for COVID-19: a Safe and Efficient Screening System against Massive Community Outbreak. Journal of Korean Medical Science. 2020;35

32. Habib H. Has Sweden's controversial covid-19 strategy been successful. BMJ. 2020;369:m2376.

33. Gémes K, Talbäck M, Modig K et al. Burden and prevalence of prognostic factors for severe COVID19 in Sweden. Eur J Epidemiol. 2020;35:401-409.

34. Kragholm K, Andersen MP, Gerds TA et al. Association between male sex and outcomes of Coronavirus Disease 2019 (Covid-19) - a Danish nationwide, register-based study. Clin Infect Dis. 2020

35. Chan JF, Yip CC, To KK et al. Improved Molecular Diagnosis of COVID-19 by the Novel, Highly Sensitive and Specific COVID-19-RdRp/Hel RealTime Reverse Transcription-PCR Assay Validated In Vitro and with Clinical Specimens. J Clin Microbiol. 2020;58

36. Won J, Lee S, Park M et al. Development of a Laboratory-safe and Low-cost Detection Protocol for SARS-CoV-2 of the Coronavirus Disease 2019 (COVID-19). Exp Neurobiol. 2020;29:107-119.

37. Yu F, Yan L, Wang N et al. Quantitative Detection and Viral Load Analysis of SARS-CoV-2 in Infected Patients. Clinical Infectious Diseases. 2020

38. Zheng Z, Yao Z, Wu K, Zheng J. Patient Follow-up after Discharge after COVID-19 Pneumonia: Considerations for Infectious Control. Journal of Medical Virology. 2020

39. Tang YW, Schmitz JE, Persing DH, Stratton CW. Laboratory Diagnosis of COVID-19: Current Issues and Challenges. J Clin Microbiol. 2020;58

40. Feng W, Newbigging AM, Le C et al. Molecular Diagnosis of COVID-19: Challenges and Research Needs. Anal Chem. 2020

41. Azzi L, Carcano G, Gianfagna F et al. Saliva is a reliable tool to detect SARS-CoV-2. J Infect. 2020;81:e45-e50.

42. Asymptomatic Transmission, the Achilles' Heel of Current Strategies to Control Covid-19. [editorial]. N Engl J Med 2020;382(22):2158.

43. Fukumoto T, Iwasaki S, Fujisawa $S$ et al. Efficacy of a novel SARS-CoV-2 detection kit without RNA extraction and purification. Int J Infect Dis. 2020

44. Deeks JJ, Dinnes J, Takwoingi Y et al. Antibody tests for identification of current and past infection with SARS-CoV-2. Cochrane Database Syst Rev. 2020;6:CD013652.

45. Zhao J, Yuan Q, Wang $\mathrm{H}$ et al. Antibody responses to SARS-CoV-2 in patients of novel coronavirus disease 2019. 2020

46. Li D, Zhang J, Li J. Primer design for quantitative real-time PCR for the emerging Coronavirus SARSCoV-2. Theranostics. 2020;10:7150-7162.

47. Sakurai A, Sasaki T, Kato S et al. Natural History of Asymptomatic SARS-CoV-2 Infection. New England Journal of Medicine. 2020

48. Kimball A, Hatfield KM, Arons $M$ et al. Asymptomatic and Presymptomatic SARS-CoV-2 Infections in Residents of a Long-Term Care Skilled Nursing Facility - King County, Washington, March 
2020. MMWR Morb Mortal Wkly Rep. 2020;69:377-381.

49. Oran DP, Topol EJ. Prevalence of Asymptomatic SARS-CoV-2 Infection: A Narrative Review. Ann Intern Med. 2020

50. Cheung KS, Hung IFN, Chan PPY et al. Gastrointestinal Manifestations of SARS-CoV-2 Infection and Virus Load in Fecal Samples From a Hong Kong Cohort: Systematic Review and Metaanalysis. Gastroenterology. 2020

51. Chen C, Gao G, Xu Y et al. SARS-CoV-2-Positive Sputum and Feces After Conversion of Pharyngeal Samples in Patients With COVID-19.[letter]. Ann Intern Med 2020;172(12):832-834.

52. An J, Liao X, Xiao T et al. Clinical characteristics of the recovered COVID-19 patients with redetectable positive RNA test. 2020

53. Kang H, Wang Y, Tong Z, Liu X. Retest positive for SARS-CoV-2 RNA of "recovered" patients with COVID-19: Persistence, sampling issues, or reinfection. J Med Virol. 2020

54. Vabret N, Britton GJ, Gruber $\mathrm{C}$ et al. Immunology of COVID-19: Current State of the Science. Immunity. 2020;52:910-941.

55. Long Q-X, Tang X-J, Shi Q-L et al. Clinical and immunological assessment of asymptomatic SARSCoV-2 infections. Nature Medicine. 2020

56. Rubino F, Amiel SA, Zimmet $P$ et al. New-Onset Diabetes in Covid-19.[letter]. N Engl J Med 2020

57. Tao SL, Wang XM, Feng YG et al. Is the presence of lung injury in COVID-19 an independent risk factor for secondary lung cancer. Med Hypotheses. 2020;143:110074.

58. Ciaglia E, Vecchione C, Puca AA. COVID-19 Infection and Circulating ACE2 Levels: Protective Role in Women and Children. Front Pediatr. 2020;8:206.

59. Tikellis C, Thomas MC. Angiotensin-Converting Enzyme 2 (ACE2) Is a Key Modulator of the Renin Angiotensin System in Health and Disease. Int J Pept. 2012;2012:256294.

60. Perrotta F, Corbi G, Mazzeo G et al. COVID-19 and the elderly: insights into pathogenesis and clinical decision-making. Aging Clin Exp Res. 2020

61. Meftahi GH, Jangravi Z, Sahraei H, Bahari Z. The possible pathophysiology mechanism of cytokine storm in elderly adults with COVID-19 infection: the contribution of "inflame-aging". Inflamm Res. 2020;69:825-839.

62. Apicella M, Campopiano MC, Mantuano M, Mazoni L, Coppelli A, Del Prato S. COVID-19 in people with diabetes: understanding the reasons for worse outcomes. The Lancet Diabetes \& Endocrinology. 2020

63. Wu Y, Feng Z, Li P, Yu Q. Relationship between $\mathrm{ABO}$ blood group distribution and clinical characteristics in patients with COVID-19. Clinica Chimica Acta. 2020;509:220-223.

64. Ellinghaus D, Degenhardt F, Bujanda L et al. Genomewide Association Study of Severe Covid19 with Respiratory Failure. N Engl J Med. 2020

65. Breiman A, Ruvën-Clouet $\mathrm{N}$, Le Pendu J. Harnessing the natural anti-glycan immune response to limit the transmission of enveloped viruses such as SARS-CoV-2. PLoS Pathog. 2020;16:e1008556.

66. Wu F, Zhou Y, Wang Z et al. Clinical characteristics of COVID-19 infection in chronic obstructive pulmonary disease: a multicenter, retrospective, observational study. J Thorac Dis. 2020;12:18111823.

67. Alqahtani JS, Oyelade T, Aldhahir AM et al. Prevalence, Severity and Mortality associated with COPD and Smoking in patients with COVID-19: A Rapid Systematic Review and Meta-Analysis. PLoS One. 2020;15:e0233147.

68. Rogado J, Pangua C, Serrano-Montero G et al. Covid-19 and lung cancer: A greater fatality rate. Lung Cancer. 2020;146:19-22.

69. Miyasaka M. Is BCG vaccination causally related to reduced COVID-19 mortality. EMBO Mol Med. 2020;12:e12661.

70. Netea MG, Giamarellos-Bourboulis EJ, DomínguezAndrés $\mathbf{J}$ et al. Trained Immunity: a Tool for Reducing Susceptibility to and the Severity of SARS-CoV-2 Infection. Cell. 2020;181:969-977.

71. Riccò M, Gualerzi G, Ranzieri S, Bragazzi NL. Stop playing with data: there is no sound evidence that Bacille Calmette-Guérin may avoid SARS-CoV-2 infection (for now). Acta Biomed. 2020;91:207-213.

72. Ye Q, Wang B, Mao J. The pathogenesis and treatment of the 'Cytokine Storm' in COVID-19. J Infect. 2020;80:607-613.

73. Tay MZ, Poh CM, Rénia L, MacAry PA, Ng LFP. The trinity of COVID-19: immunity, inflammation and intervention. Nat Rev Immunol. 2020;20:363374.

74. Iba T, Levy JH, Levi M, Connors JM, Thachil J. Coagulopathy of Coronavirus Disease 2019. Crit Care Med. 2020

75. McGonagle D, O’Donnell JS, Sharif K, Emery P, Bridgewood C. Immune mechanisms of pulmonary intravascular coagulopathy in COVID-19 pneumonia. The Lancet Rheumatology. 2020;2:e437-e445.

76. Felsenstein S, Herbert JA, McNamara PS, Hedrich CM. COVID-19: Immunology and treatment options. Clin Immunol. 2020;215:108448.

77. Radzikowska U, Ding M, Tan G et al. Distribution of ACE2, CD147, CD26 and other SARS-CoV-2 associated molecules in tissues and immune cells in health and in asthma, COPD, obesity, hypertension, and COVID-19 risk factors. Allergy. 2020

78. Ayres JS. A metabolic handbook for the COVID-19 pandemic. Nat Metab. 2020

79. Gao J, $\mathrm{Hu}$ S. Update on use of chloroquine/hydroxychloroquine to treat coronavirus disease 2019 (COVID-19). Biosci Trends. 2020;14:156-158.

80. Salvi R, Patankar P. Emerging pharmacotherapies for COVID-19. Biomed Pharmacother. 2020;128:110267.

81. Esposito S, Noviello S, Pagliano P. Update on treatment of COVID-19: ongoing studies between promising and disappointing results. Infez Med. 2020;28:198-211. 
82. Cao B, Wang Y, Wen D et al. A Trial of LopinavirRitonavir in Adults Hospitalized with Severe Covid-19. N Engl J Med. 2020;382:1787-1799.

83. Elfiky AA. Ribavirin, Remdesivir, Sofosbuvir, Galidesivir, and Tenofovir against SARS-CoV-2 RNA dependent RNA polymerase (RdRp): A molecular docking study. Life Sci. 2020;253:117592.

84. Wang Y, Zhang D, Du G et al. Remdesivir in adults with severe COVID-19: a randomised, doubleblind, placebo-controlled, multicentre trial. Lancet. 2020;395:1569-1578.

85. Beigel JH, Tomashek KM, Dodd LE et al. Remdesivir for the Treatment of Covid-19 Preliminary Report. N Engl J Med. 2020

86. Bloch EM, Shoham S, Casadevall A et al. Deployment of convalescent plasma for the prevention and treatment of COVID-19. J Clin Invest. 2020;130:2757-2765.

87. Xia X, Li K, Wu L et al. Improved Clinical Symptoms and Mortality on Severe/Critical COVID-19 Patients Utilizing Convalescent Plasma Transfusion. Blood. 2020

88. Valk SJ, Piechotta V, Chai KL et al. Convalescent plasma or hyperimmune immunoglobulin for people with COVID-19: a rapid review. Cochrane Database of Systematic Reviews. 2020

89. Li L, Zhang W, Hu Y et al. Effect of Convalescent Plasma Therapy on Time to Clinical Improvement in Patients With Severe and Life-threatening COVID-19: A Randomized Clinical Trial. JAMA. 2020

90. Monteil V, Kwon H, Prado P et al. Inhibition of SARS-CoV-2 Infections in Engineered Human Tissues Using Clinical-Grade Soluble Human ACE2. Cell. 2020;181:905-913.e7.

91. Inal JM. Decoy ACE2-expressing extracellular vesicles that competitively bind SARS-CoV-2 as a possible COVID-19 therapy. Clin Sci (Lond). 2020;134:1301-1304.

92. Sriram K, Insel PA. A hypothesis for pathobiology and treatment of COVID-19: The centrality of ACE1/ACE2 imbalance. Br J Pharmacol. 2020

93. Alattar R, Ibrahim TBH, Shaar $\mathrm{SH}$ et al. Tocilizumab for the treatment of severe coronavirus disease 2019. Journal of Medical Virology. 2020

94. Roschewski M, Lionakis MS, Sharman JP et al. Inhibition of Bruton tyrosine kinase in patients with severe COVID-19. Sci Immunol. 2020;5

95. Dexamethasone in the management of covid -19 . [editorial]. BMJ 2020;370:m2648.

96. Mahase E. Covid-19: Demand for dexamethasone surges as RECOVERY trial publishes preprint. BMJ. 2020m2512.

97. Yin S, Huang M, Li D, Tang N. Difference of coagulation features between severe pneumonia induced by SARS-CoV2 and non-SARS-CoV2. J Thromb Thrombolysis. 2020

98. Zhang Y, Xiao M, Zhang S et al. Coagulopathy and Antiphospholipid Antibodies in Patients with Covid-19. New England Journal of Medicine. 2020;382:e38.
99. Magro G. COVID-19: Review on latest available drugs and therapies against SARS-CoV-2. Coagulation and inflammation cross-talking. Virus Res. 2020;286:198070.

100. Watson RA, Johnson DM, Dharia RN, Merli GJ, Doherty JU. Anti-coagulant and anti-platelet therapy in the COVID-19 patient: a best practices quality initiative across a large health system. Hosp Pract (1995). 20201-11.

101. Guan WJ, Liang WH, Zhao Y et al. Comorbidity and its impact on 1590 patients with COVID-19 in China: a nationwide analysis. Eur Respir J. 2020;55

102. Verdecchia P, Angeli F, Mazzotta G, Gentile G, Reboldi G. The renin angiotensin system in the development of cardiovascular disease: role of aliskiren in risk reduction. Vasc Health Risk Manag. 2008;4:971-981.

103.Curfman G. Renin-Angiotensin-Aldosterone Inhibitors and Susceptibility to and Severity of COVID-19. JAMA. 2020

104. Sukumaran V, Tsuchimochi H, Tatsumi E, Shirai M, Pearson JT. Azilsartan ameliorates diabetic cardiomyopathy in young $\mathrm{db} / \mathrm{db}$ mice through the modulation of ACE-2/ANG 1-7/Mas receptor cascade. Biochem Pharmacol. 2017;144:90-99.

105.Gao C, Cai Y, Zhang K et al. Association of hypertension and antihypertensive treatment with COVID-19 mortality: a retrospective observational study. Eur Heart J. 2020;41:2058-2066.

106.Zhang P, Zhu L, Cai J et al. Association of Inpatient Use of Angiotensin-Converting Enzyme Inhibitors and Angiotensin II Receptor Blockers With Mortality Among Patients With Hypertension Hospitalized With COVID-19. Circ Res. 2020;126:1671-1681.

107.Fosb $\varnothing 1$ EL, Butt JH, Østergaard L et al. Association of Angiotensin-Converting Enzyme Inhibitor or Angiotensin Receptor Blocker Use With COVID-19 Diagnosis and Mortality. JAMA. 2020

108.Meng J, Xiao G, Zhang J et al. Renin-angiotensin system inhibitors improve the clinical outcomes of COVID-19 patients with hypertension.[letter]. Emerg Microbes Infect 2020;9(1):757-760.

109.Ruilope LM, Tamargo J, Ruiz-Hurtado G. Reninangiotensin system inhibitors in the COVID-19 pandemic: consequences of antihypertensive drugs. Eur Heart J. 2020;41:2067-2069.

110. Rao S, Lau A, So HC. Exploring Diseases/Traits and Blood Proteins Causally Related to Expression of ACE2, the Putative Receptor of SARS-CoV-2: A Mendelian Randomization Analysis Highlights Tentative Relevance of Diabetes-Related Traits. Diabetes Care. 2020;43:1416-1426.

111.Zhu L, She ZG, Cheng X et al. Association of Blood Glucose Control and Outcomes in Patients with COVID-19 and Pre-existing Type 2 Diabetes. Cell Metab. 2020;31:1068-1077.e3.

112.Zhu FC, Li YH, Guan XH et al. Safety, tolerability, and immunogenicity of a recombinant adenovirus type-5 vectored COVID-19 vaccine: a doseescalation, open-label, non-randomised, first-inhuman trial. Lancet. 2020;395:1845-1854.

113. Cohen J. Vaccine designers take first shots at COVID-19. Science. 2020;368:14-16. 
114.Out of the frying pan and into the fire? Due diligence warranted for ADE in COVID-19. [editorial]. Microbes Infect 2020
115.Iwasaki A, Yang Y. The potential danger of suboptimal antibody responses in COVID-19. Nat Rev Immunol. 2020;20:339-341. 